\title{
PATCH CLOSURE OF THE AORTIC ANULUS IN A RECIPIENT OF A VENTRICULAR ASSIST DEVICE
}

\author{
James C. Stringham, MD, David A. Bull, MD, and S. V. Karwande, MD, Salt Lake City, Utah
}

Management of the prosthetic aortic valve continues to be a challenge in those patients who require left ventricular mechanical assistance. If left in situ, the indwelling mechanical prosthesis may increase the risk of cerebral thromboembolism. A frequent solution has been valve re-replacement with a bioprosthesis, which may reduce the thromboembolic risk but may not obviate the need for anticoagulation. We describe in this report our experience with such a patient and a novel approach to avoid valve re-replacement with patch closure of the aortic anulus.

Clinical summary. A 55-year-old man who had received a Starr-Edwards aortic valve (Baxter Healthcare Corp, Edwards Division, Santa Ana, Calif) some 25 years earlier had a massive anterolateral myocardial infarction. This resulted in severe mitral regurgitation, pulmonary edema, and cardiogenic shock. An angioplasty of the occluded left anterior descending coronary artery was performed successfully but did not restore ventricular function. He was transferred to our center intubated with an intra-aortic balloon pump in place and supported with multiple inotropic agents. After clinical stabilization and rapid work-up for transplantation had been completed, it became apparent that mechanical ventricular assistance was his only chance for survival until a donor heart became available.

The patient underwent successful placement of a TCI HeartMate 1000 IP left ventricular assist device (LVAD; Thermo Cardiosystems Inc, Woburn, Mass). At the time of surgery, we thought that the existing prosthetic aortic valve should be removed to prevent the risk of perivalvular thromboembolism and the need for anticoagulation. A vertical aortotomy was performed anteriorly, which was later used for the outflow graft anastomosis. Attempts at permanent closure of the ball valve were unsuccessful because the ball could not be pierced with a needle. Through this exposure the struts of the valve were transected at their junction with the sewing ring and removed together with the ball valve, leaving the original and well-incorporated sewing ring in place. The aortic anulus

From the Division of Cardiothoracic Surgery and the UTAH Cardiac Transplant Program, University of Utah School of Medicine, Salt Lake City, Utah.

Received for publication Jan 19, 2000; accepted for publication Jan $25,2000$.

Address for reprints: James C. Stringham, MD, Division of Cardiothoracic Surgery, University of Utah School of Medicine, 50 North Medical Dr, Salt Lake City, UT 84132.

J Thorac Cardiovasc Surg 2000;119:1293-4

Copyright (c) 2000 by The American Association for Thoracic Surgery

$0022-5223 / 2000 \$ 12.00+0 \quad \mathbf{1 2 / 5 4 / 1 0 6 0 3 5}$

doi: $10.1067 / \mathrm{mtc} .2000 .106035$ was then closed with a Dacron patch buttressed on the aortic surface with autologous pericardium and secured with interrupted polypropylene stitches placed through the anulus and the indwelling sewing ring.

The patient recovered and left the intensive care unit 13 days later with only aspirin for anticoagulation. A transesophageal echocardiogram performed on postoperative day 10 revealed the aortic root to be entirely free of thrombus. He tolerated venting of the pneumatic device in the supine position without adverse sequelae except mild lightheadedness. After 60 days of LVAD support, a suitable donor heart became available, and he underwent transplantation without complication. On explantation of the native heart, the aortic root and left ventricular outflow tract were completely free of thrombus or pannus formation. The coronary orifices were free of obstruction, and a smooth neoendothelialization had occurred on both the aortic and ventricular surfaces of the annular patch (Fig 1). The patient subsequently did well and was discharged 12 days after transplantation.

Comment. Mechanical circulatory assistance can be lifesaving for those with left ventricular decompensation. However, the appropriate treatment paradigm for those who have previously undergone prosthetic aortic valve replacement remains uncertain. Indeed several authors have stated that the presence of a prosthetic aortic valve may be considered a contraindication to LVAD implantation. ${ }^{1,2}$ Burton and colleagues $^{3}$ have reported the case of a patient with a StarrEdwards valve who received LVAD support. Although he continued to receive heparin during support and was without thromboembolic events, thrombi were found on all three struts of the valve at explantation.

One possible approach is to replace the prosthetic valve with a bioprosthesis, thus possibly reducing the risk of thromboembolism and the need for long-term anticoagulation. Although this has been advocated by some, ${ }^{4}$ it adds significant expense and precious time to the procedure. Furthermore, Adamson and associates ${ }^{5}$ have reported complete thrombosis of a porcine bioprosthesis in an LVAD recipient despite warfarin anticoagulation for the first month of support, although no cerebral or peripheral embolization occurred. This patient's native heart was able to eject through the LVAD with the aortic valve obstructed when support was interrupted.

Patch closure of the aortic anulus has both advantages and disadvantages. It is quicker than valve re-replacement, necessitating no dissection of the previously placed sewing ring since the patch can be attached to the sewing ring directly. It can be accomplished through the same aortotomy that is used for anastomosis of the LVAD outflow graft. It is also substan- 

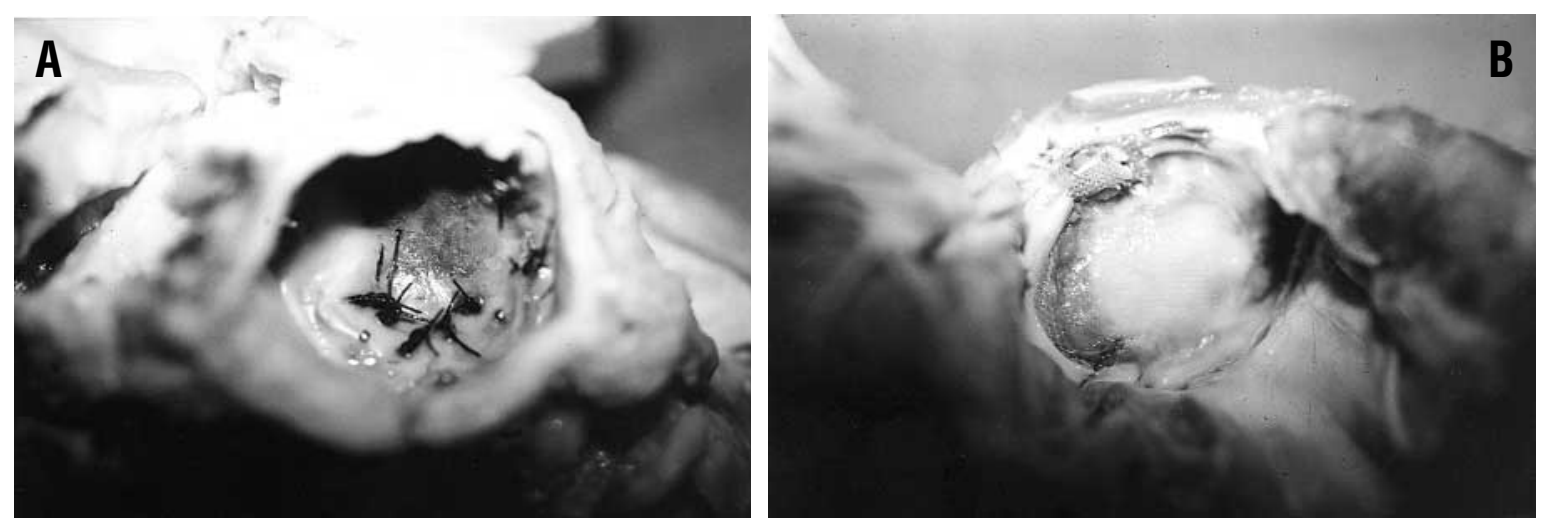

Fig 1. Photographs of the explanted aortic anulus, showing the smoothly endothelialized surface of the annular patch on both the aortic (A) and ventricular (B) surfaces.

tially less costly than a new bioprosthesis for an LVAD recipient, who must expend large amounts of money for this expensive procedure. Furthermore, this procedure does not appear to stimulate thrombus formation in either the aortic root, which might obstruct the coronary orifices, or the left ventricular chamber, which could be a source of cerebral thromboembolism.

The major disadvantage, however, is that if the left ventricular outflow tract is closed, endogenous left ventricular function may be eliminated as a back-up in the event of device failure. Nevertheless, it appears likely that the left ventricle is able to eject through the LVAD itself in the event of outflow tract obstruction. This is evident from the absence of loss of consciousness or other severe neurologic symptoms in our patient during the 15 - to 20 -second venting intervals of the pneumatic device used in this report, as well as the case of aortic valve thrombosis cited earlier. ${ }^{4}$

This procedure may also be useful in the patient with native aortic valve regurgitation or in whom aortic regurgitation may develop during prolonged LVAD support. The native aortic valve is not accustomed to the constant pressure of LVAD support, since it is normally required to withstand only the diastolic aortic back pressure during normal ventricular function. This may become more important as the duration of mechanical support increases for those awaiting transplanta- tion and particularly for those who receive LVAD support as destination therapy rather than a shorter-term bridge.

In conclusion, patch closure of the aortic anulus is another alternative for management of LVAD recipients with indwelling prosthetic aortic valves or poor native aortic valve function.

\section{REFERENCES}

1. Frazier OH, Rose EA, Macmanus Q, Burton NA, Lefrak EA, Poirier VL, et al. Multicenter clinical evaluation of the HeartMate 1000 IP left ventricular assist device. Ann Thorac Surg 1992;53:1080-90.

2. Jaski BE, Branch KR, Dasse KA, Dembitsky WP. Diagnosis and treatment of complications in patients implanted with a TCI left ventricular assist device. J Interven Cardiol 1995;8:275-82.

3. Burton NA, Lefrak EA, Macmanus Q, Hill A, Marino JA, Speir AM, et al. A reliable bridge to cardiac transplantation: the TCI left ventricular assist device. Ann Thorac Surg 1993;55:1425-31.

4. Oz MC, Goldstein DJ, Rose EA. Preperitoneal placement of ventricular assist devices: an illustrated stepwise approach. J Card Surg 1995;10:288-94.

5. Adamson RM, Dembitsky WP, Jaski BE, Daily PO, Moreno R, Kim JC, et al. Left ventricular assist device support of medically unresponsive pulmonary hypertension and aortic insufficiency. ASAIO J 1997;43:365-9. 